\title{
Gamification Applied in Computer Science Education: A Preliminary Approach
}

\author{
Bogdan IANCU \\ The Bucharest University of Economic Studies \\ bogdan.iancu@ie.ase.ro
}

This paper presents a preliminary approach for implementing a gamification-based system that can be used by the bachelor's degree program students from our faculty in order to improve their computer science learning experience. Based on the state-of-art elements specific to gamification and on a briefly literature review of the existing gamification platforms and studies related to its efficiency when it comes to learning computer science, we identified a platform, in the name of Kahoot, that can be used as a preliminary step in our gamification approach. The obtained results and the students' feedback look promising and open the door for future additions and improvements.

Keywords: gamification, education, computer science, software engineering, e-learning DOI: $10.12948 / \mathrm{ei} 2019.01 .06$

1 Introduction

In the previous years, a rapid growth of elearning software solutions inspired by video games was observed. Usually called "gamification", this process uses a group of already existing concepts and it is based on the human-computer interaction in the lack of a real professor. There are different approaches used like serious games, universal games, VR (Virtual Reality) or AR (Augmented Reality) games, funny/entertainment games. While some authors consider those to be part of gamification, others emphasize that gamification is a different concept with its own characteristics [1].

Under the term "gamification" we can find a large number of apps with different usages across a large number of domains like finance, health, education, sustainability, journalism, entertainment. Some companies are even offering "Gamification as a Service", APIs (Application Programming Interfaces) that allow the usage of rewards, points, badges, levels, rankings and other game-specific elements in non-game environments. An example of such a platform is Captain Up, a solution which can add gamification capabilities to WordPress websites or GitHub repositories [2]. The clients of this service can add their own levels, badges or points awarded for specific scenarios (figure 1).
Gamification, as a term, originates in the digital media industry, first occurrence of it being recorded in 2008. Nevertheless, the term was not used on a large scale until the last part of 2010. Some other terms are used even today, but gamification remains the most popular one. When it comes to define the term, the most widely used definition of gamification is "the usage of game-specific elements in a non-game context" [3].

The human learning process has used games for a very long time in order to deepen some knowledge, especially when we talk about young children. No matter the age, the game was used in the past especially when the relation between the student and the professor was a direct one. With the rise of MOOCs (Massive Online Open Courses) from nowadays, the usage of games becomes somehow mandatory in order to replace the direct studentprofessor interaction [4]. By using game-specific techniques in the learning process, the expected result is to trigger a learning behavior and to increase the efficiency and the engagement. Humans, especially young adults (as the B. Sc. students are for example), are big fans of games. In order to change or trigger a new behavior, the student needs an extrinsic motivation factor and the capacity to deal with challenges [5], elements that are present in game-based environments. 


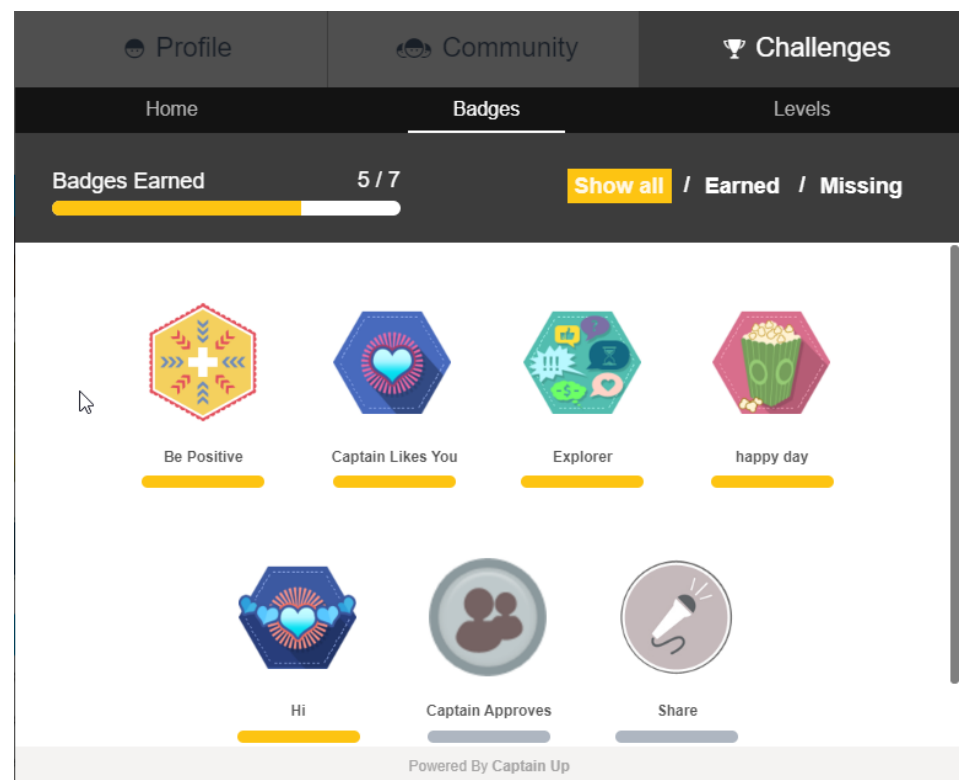

Fig. 1. Captain Up's interface for a sample WordPress site. Source: https://blog.captainup.com/

Gamification also implies the social interaction with the other players. In an e-learning environment, the lack of real human interactions can be replaced by a gamification experience, from a pedagogical point of view. In order to trigger a new behavior, usually a new impulse is needed. As long as the user is aware that only the completion of some task will give him or her the promised achievement, they will continue the task. Examples of achievements can be: earning resources, unlocking new elements or sharing something with others.
A successful example of applying gamification elements to an e-learning platform is Duolingo, an website / mobile app dedicated to learning foreign languages [6]. The platform is based on exercises divided into different difficulty levels that can be unlocked based on the scores achieved at previous exercises (figure 2). Duolingo is extremely efficient, as efficient as learning a foreign language throughout an university course, according to their internal study [7] (34 hours spent on Duolingo are the equivalent of a whole university semester of 11 weeks).

\section{Gamification poured into every lesson.}
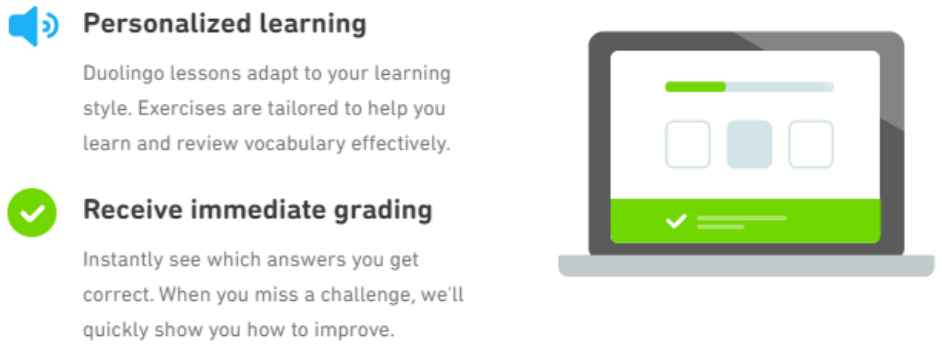

Fig. 2. The gamification elements of the Duolingo app. Image source: https://www.duolingo.com/ 
Other examples of platforms related to the computer science domain that are using gamification elements are Codecademy [8] and CodeSignal [9], both of them with positive effects on players' retention and engagement [10].

\section{Literature review}

There are multiple peer-reviewed studies that emphasize that gamification can be applied successfully in the process of learning new programming languages and that validate gamification elements by improving the curriculum of different software engineering courses in this regard. In [11] authors identify the engagement as the major factor needed in order to determine the students to better learn computer science and that gamification can play the main role in increasing the engagement. The identified downside is that there is also the need to develop some antiplagiarism techniques because such a system might allow cheating.

Paper [12] adds the social networking component to gamification by allowing the users to interact with each other and share their results, while [13] states that the best results are obtained when a specific lesson lasts between 15 and 20 minutes.

In [14] several players classes are identified starting from the Bartle taxonomy of player types: explorers, achievers, socializers and winners, together with the core tools that need to be implemented in any gamification system designed for learning computer science-related topics: points system, levels, leaderboards, badges, onboarding experience, social engagement and content unlocking. Other tools/elements identified in [15] include knowledge maps, goals and progress indicators. Any gamification platform needs to implement a relevant subset of these elements, otherwise it tends to transform itself into just a "pointification" system only according to [16].

Study [17] identifies gamification as a fast growing tendency and, based on an internal survey, states that more than $90 \%$ of the students liked the implementation of gamification techniques in Software Engineering courses.

Other studies like [18], [19] and [20] also report good results when applying gamification in the studying process of computer sciences, programming languages and promote the usage of these techniques in universities.

\section{Our preliminary approach}

Motivated by the unsatisfactory results obtained at the final exam by some our students from the bachelor's degree program in Computer Science, we took an initiative to add some gamification elements to our laboratories for the Objected Oriented Programming and Multiparadigm Programming in Java disciplines. The preliminary step, which this section will focus on, was the usage of learning games in the form of interactive quizzes at the end of each laboratory. In this way we tested the students' focus during the labs and also if they processed the information required for the final exam. Two different platforms were taken into consideration at the beginning: Kahoot [21] and Socrative [22], but we sticked to Kahoot because of its grater popularity and for subjective reasons.

Kahoot is a platform that allows the creation and playing of interactive quizzes with single or multiple correct answers. The questions are displayed one at a time on the teacher's projected screen together with the possible answers. The students have a specific limited time to answer, by selecting the proper color/figure from their screen which can be a mobile phone or a laptop (figure 3). Only chosen participants can join a test because a randomly generated PIN code is necessary, code that expires at the end of the test. Students are graded based on the correctness of their answer and on their rapidity. After each question a temporary leaderboard is displayed and a final podium is presented at the end. Other options, present in the free version of the platform, include the randomizing of the questions and/or answers, the possibility to add just true/false questions or to ability to play in team vs team mode, instead of individual mode.

The created quizzes consisted of a mix of pure theoretical questions like "What is a virtual 
method?" for example, and questions that included a code snippet that needed to be evaluated in order to identify the correct answer (as visible in figure 3 ). A specific feedback was given by the professor after the time limit passed for each and every question. Each quiz was made up of 10 questions and the time limit was between 15 seconds (theoretical questions) and 30 seconds (code snippet based questions). For Object Oriented Programming we graded the average of all the Kahoot tests with $10 \%$ from the final grade, while for Multiparadigm Programming in Java we did the tests just to gather experience, without taking into the consideration the results.

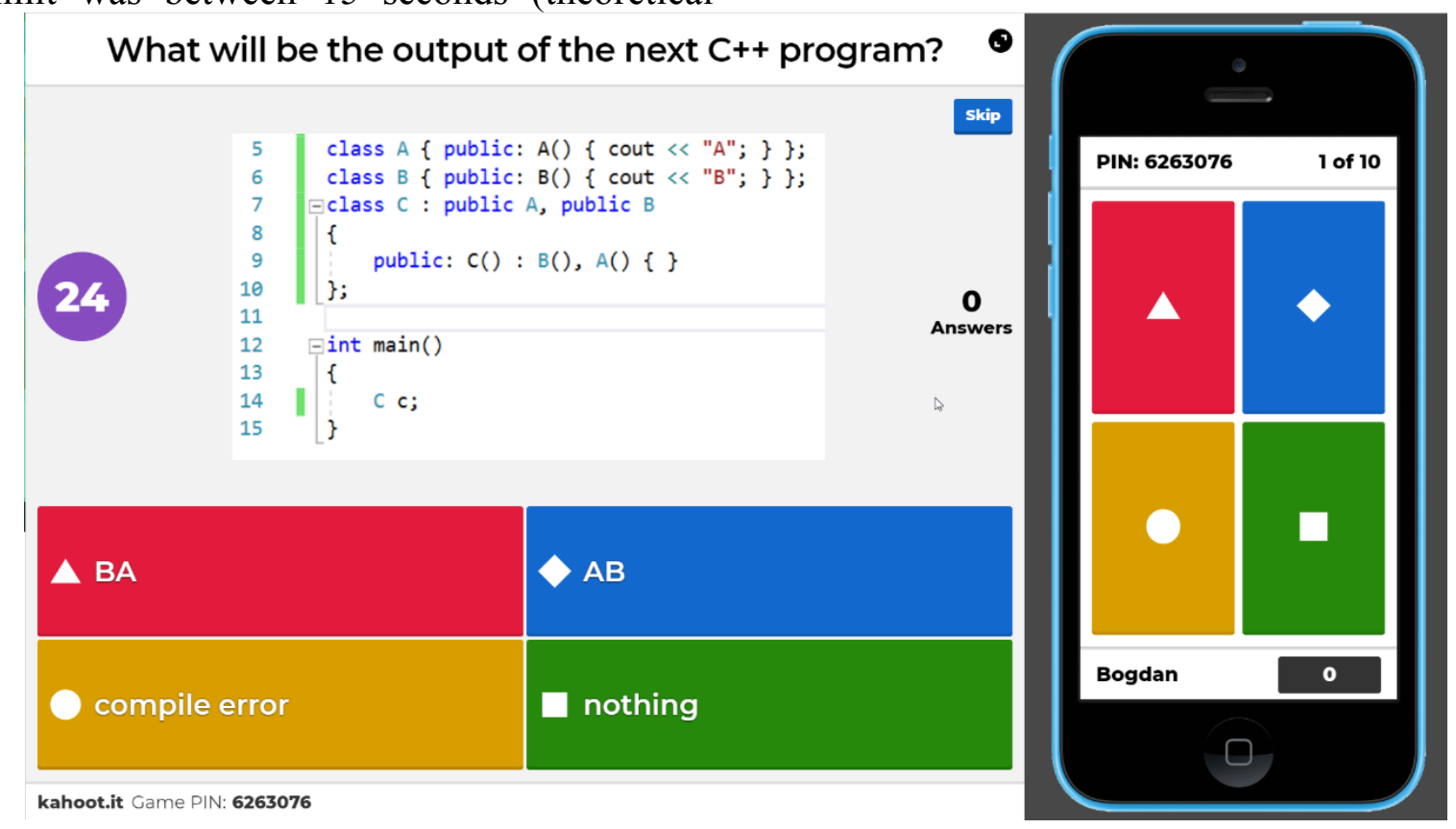

Fig. 3. The user interface of Kahoot: the projected image (left) and the image visible on the students' phones (right)

\section{Obtained results}

We evaluated the results in the first phase by using an $\mathrm{A} / \mathrm{B}$ testing technique. We have randomly chosen a group of 50 students (A) which participated in the program and compared them with another randomly chosen sample of 50 students who didn't participate (B). The participants involved in the gamification program (A) for Object Oriented Programming obtained an average grade at the final exam of 6.41 out of 10 , while the others (B) 6.5 out of 10 , so we didn't find any statistical differences in this case. When it comes to Java Programming, the students from group A obtained in average 5.34 points out of 10 on their final exam, while group B, 5.04. We concluded that there are no significant statistical differences in this case either.

In order to see if there is any relation between the points won at the Kahoot tests done during the semester and the final grade for Object
Oriented Programming (OOP) we did a Pearson Correlation Test. We did it just for this discipline only due to the fact that, as stated earlier, the results obtained at Java Programming weren't aggregated, the main scope of Kahoot being to gain experience with the platform. The obtained correlation value was 0.46 which means that there is a medium to strong correlation between the points obtained at the Kahoot tests and the grade obtained at the exam (the $p$ value was below 0.05 so the correlation coefficient is statistically significant). The correlation is also visible in the graphical representation of the two series (figure 4).

One may think that the students with prior object oriented programming experience scored better during the semester and at the final exam because of their existing knowledge. We should emphasize the fact that there is no other OOP related course prior to this one, and these students, if exist, are the exceptions. Another factor that determined us to continue the 
gamification process of the computer science laboratories was the positive feedback received at the end of the semester: "the whole idea with the Kahoot was very interesting", "the Kahoot tests made us pay more attention to what was explained at the labs during the semester", "I loved the Kahoots and the fact that there was an explanation after each question", just to name a few sentences from the students' reviews of the laboratories.

\section{Relation between final grade and Kahoot tests points}

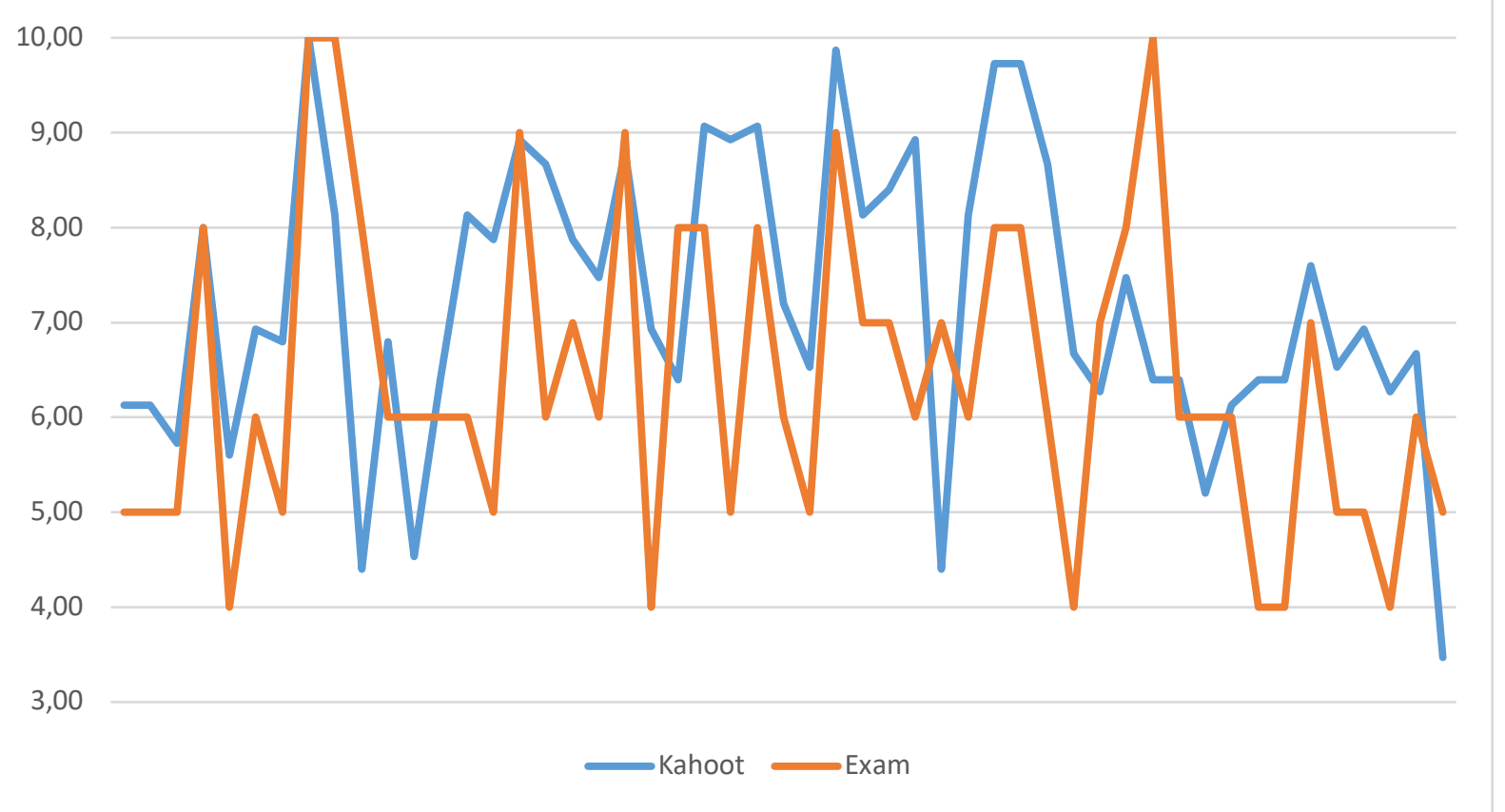

Fig. 4. Chart representing the values of the two series (normalized to a 1-10 interval)

\section{Conclusions}

This study presented the preliminary steps done for creating a gamification system for the students from our faculty by integrating a subset of the gamification tools like points systems, leaderboards and progress indicators in the form of Kahoot tests. Motivated by the results reported by other researchers when they applied these techniques for the computer science courses and by very popular apps like Duolingo, we took the initiative to do the same at least for some pilot laboratories. The results obtained after the first year are encouraging. It seems that there is a medium correlation between the points gathered by students when playing the gamified tests and their final grade from the exam. Also, based on their feedback, they seem to enjoy the experience very much. In the next period we will try to use a mix of platforms (until we finish with the experiments and we can develop a custom platform) that allow us to include some other gamification elements like knowledge maps, goals, badges, levels and content unlocking. We also have an ongoing study that wants to identify which factors play a major role in the final grade obtained at the OOP exam (how much they enjoy programming, the weekly hours spent writing programs, the prior programming knowledge, the grades obtained at previous computer science courses and others minor factors). When the results of this study will be ready, we will try to improve these factors with the use of gamification.

\section{Acknowledgment}

This paper was co-financed from the Human Capital Operational Program 2014-2020, project number POCU / 380/6/13/125245 no. 36482 / 23.05.2019 "Excellence in interdisciplinary $\mathrm{PhD}$ and post-PhD research, career alternatives through entrepreneurial initiative (EXCIA)", coordinator The Bucharest University of Economic Studies. 


\section{References}

[1] B. Iancu and I. Smeureanu, "The Usage of Ontologies for the Discovery and Coupling of Learning Active Components (PhD Thesis)," The Bucharest University of Economic Studies, Bucharest, 2015.

[2] "Captain Up - Engagement Platform as a Service," November 2019. [Online]. Available: https://captainup.com/. [Accessed November 2019].

[3] S. Deterding, D. Dixon, R. Khaled and L. Nacke, "From game design elements to gamefulness: defining "gamification"," in Proceedings of the 15th international academic MindTrek conference: Envisioning future media environments, 2011.

[4] A. Vaibhav and G. Pooja, "Gamification of MOOCs for increasing user engagement," in 2014 IEEE International Conference on MOOC, Innovation and Technology in Education (MITE), 2014.

[5] C. I. Muntean, "Raising engagement in elearning through gamification," in Proc. 6th International Conference on Virtual Learning ICVL, 2011.

[6] "Duolingo - The world's best way to learn a language," November 2019. [Online]. Available: https://www.duolingo.com/. [Accessed November 2019].

[7] I. Garcia, "Learning a language for free while translating the web. does duolingo work?," English Linguistics, vol. 3, no. 1, p. 19, 2013.

[8] "Codecademy," November 2019. [Online]. https://www.codecademy.com/.

[Accessed November 2019].

[9] "Coding Tests and Assessments for Technical Hiring - CodeSignal," November 2019. [Online]. Available: https://codesignal.com/. [Accessed November 2019].

[10] J. Hamari, K. Jonna and S. Harri, "Does Gamification Work?-A Literature Review of Empirical Studies on Gamification," HICSS, vol. 14, no. 2014, pp. 3025-3034, 2014.

[11] M.-B. Ibanez, A. Di-Serio and C. Delgado-Kloo, "Gamification for engaging computer science students in learning activities: A case study," IEEE Transactions on learning technologies, vol. 7, no. 3, pp. 291-301, 2014.

[12] C. Li, Z. Dong, R. H. Untch and M. Chasteen, "Engaging computer science students through gamification in an online social network based collaborative learning environment," International Journal of Information and Education Technology, vol. 3, no. 1, p. 72, 2013.

[13] I. V. Osipov, E. Nikulchev, A. A. Volinsky and A. Y. Prasikova, "Study of gamification effectiveness in online elearning systems," International Journal of advanced computer science and applications, vol. 6, no. 2, pp. 71-77, 2015.

[14] A. Iosup and D. Epema, "An experience report on using gamification in technical higher education," in Proceedings of the 45th ACM technical symposium on Computer science education, 2014.

[15] B. B. Morrison and B. DiSalvo, "Khan academy gamifies computer science," in Proc. 45th ACM Techn. Symp. Comput. Sci. Educ., 2014.

[16] O. Pedreira, F. García, N. Brisaboa and M. Piattini, "Gamification in software engineering-A systematic mapping," Information and software technology, no. 57, pp. 157-168, 2015.

[17] V. Uskov and B. Sekar, "Gamification of software engineering curriculum," in 2014 IEEE Frontiers in Education Conference (FIE) Proceedings, 2014.

[18] K. Browne and C. Anand, "Gamification and serious game approaches for introductory computer science tablet software," in Proceedings of the First International Conference on Gameful Design, Research, and Applications, 2013.

[19] S. O'Donovan, J. Gain and P. Marais, "A case study in the gamification of a university-level games development course," in Proceedings of the South African Institute for Computer Scientists and Information Technologists Conference, 2013. 
[20] J. Swacha and P. Baszuro, "Gamification-based e-learning platform for computer programming education," in $X$ World Conference on Computers in Education, 2013.

[21] "Kahoot! | Learning Games | Make Learning Awesome!," November 2019.
[Online]. Available: https://kahoot.com/. [Accessed November 2019].

[22] "Socrative," November 2019. [Online]. Available: https://socrative.com/. [Accessed November 2019].

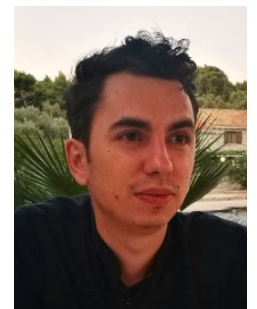

Bogdan IANCU has graduated The Faculty of Cybernetics, Statistics and Economic Informatics from The Bucharest University of Economic Studies in 2010. He has a master's degree in Economic Informatics (2012) and a PhD degree in Economic Informatics achieved in 2015 in the field of Ontologies and eLearning. He is an Assistant Lecturer in The Department of Economic Informatics from The Bucharest University of Economic Studies. His current research focuses on semantic technologies and ontologies innovations. Other fields of interest include machine learning, cybersecurity, mobile devices and IoT. 